REVISIONS (May 28, 2016)

\title{
Should we build wind farms close to load or invest in transmission to access better wind resources in remote areas? A case study in the MISO region
}

\author{
Julian V. Lamy ${ }^{1}$, Paulina Jaramillo, Inês L. Azevedo, Ryan Wiser
}

\begin{abstract}
Wind speeds in remote areas are sometimes very high, but transmission costs to access these locations can be prohibitive. We present a conceptual model to estimate the economics of accessing high quality wind resources in remote areas to comply with renewable energy policy targets, and apply the model to the Midwestern grid (MISO) as a case study. We assess the goal of providing $40 \mathrm{TWh}$ of new wind generation while minimizing costs, and include temporal aspects of wind power (variability costs and correlation to market prices) as well as total wind power produced from different farms. We find that building wind farms in North/South Dakota (windiest states) compared to Illinois (less windy, but close to load) would only be economical if the incremental transmission costs to access them were below $\$ 360 / \mathrm{kW}$ of wind capacity (break-even value). Historically, the incremental transmission costs for wind development in North/South Dakota compared to in Illinois are about twice this value. However, the break-even incremental transmission cost for wind farms in Minnesota/Iowa (also windy states) is $\$ 250 / \mathrm{kW}$, which is consistent with historical costs. We conclude that wind development in Minnesota/Iowa is likely more economical to meet MISO renewable targets compared to North/South Dakota or Illinois.
\end{abstract}

Keywords: Wind Power; Transmission; Variability; Decision Making Under Uncertainty

\footnotetext{
${ }^{1}$ Corresponding Author: $\mathrm{PhD}$ candidate, Carnegie Mellon University, Engineering \& Public Policy, 202-257-8377 (phone), (412) 268-3757 (fax), jlamy@andrew.cmu.edu
} 


\section{INTRODUCTION}

Replacing conventional generation with wind power could reduce greenhouse gas (GHG) emissions and provide a sustainable, low-carbon source of energy. However, deciding where to build wind farms is not trivial. Many of the highest quality onshore wind resources in the United State (U.S.) are located in the Midwest, often in areas that are far away from load centers and that therefore require large transmission investments. An alternative to accessing these distant resources is to build farms closer to electricity consumers where wind power output may not be as high, but less transmission investment is needed. This paper provides a modeling framework that policymakers can use to inform where to build wind farms given these tradeoffs.

We focus on the Midwestern electricity grid, MISO (Midcontinent Independent System Operator), which spans 15 states. In 2012, $21 \%$ of total electricity sales were within Illinois, the most populous state in MISO. Including sales in the neighboring states of Missouri and Indiana, this percentage increases to 49\%. In contrast, states that are more remote from major load centers such as North and South Dakota collectively account for only 4\% of MISO's electricity sales ${ }^{2}$ (U.S. Energy Information Administration, 2012). Compared to wind farms in North Dakota, Illinois wind farms tend to have lower transmission interconnection costs, as there is already a robust network of existing infrastructure (high voltage lines, substations, etc.). Based on data gathered from MISO's transmission interconnection queue, median transmission upgrade costs for new wind farms in Illinois are about \$33/kilowatt $(\mathrm{kW})$ of installed wind capacity, compared to $\$ 762 / \mathrm{kW}$ in North Dakota (see Table 1 in Section 2 for more details). This does not mean that North Dakota wind farms need to build dedicated, long-distance transmission lines into major load centers in Illinois, but it is likely more costly to upgrade the more limited transmission infrastructure in North Dakota compared to Illinois.

\footnotetext{
${ }^{2}$ For simplicity, we used total electricity sales within each state that is in MISO, even though some states are only partially in MISO. We did not include states within MISO's Southern region since they are outside the scope of our study's geographical focus.
} 
There may be benefits to building wind farms in remote areas if the total amount of power produced is larger than in closer locations and if it is produced at times when the electricity generated is more valuable. Consider again the example of North and South Dakota compared to Illinois. According to power output data of hypothetical wind farms from the National Renewable Energy Laboratory (NREL), North and South Dakota wind farms result in average capacity factors of $43 \%$ compared to $40 \%$ in Illinois (“Eastern Wind Interconnection and Transmission Study (EWITS)," 2012). At first glance this difference may appear small, but it accounts for a cost difference of $\$ 1.4$ billion in upfront costs when trying to meet a wind generation target of 40 terawatt-hours (TWh) per year (equivalent to renewable targets in MISO), assuming that installed capital cost for wind farms are $\$ 1,750 / \mathrm{kW}$. Accessing higher capacity factor wind sites in remote areas could substantially reduce costs to meet policy goals, even if transmission upgrade costs for these sites are higher. Furthermore, the timing of wind power production is critical. Wind farms are most valuable when they produce during times of high energy demand, which corresponds to higher prices in energy markets, and a larger payment in capacity markets (in MISO, capacity payments for wind farms are based on the capacity factor of wind farms during peak load hours (MISO, 2013a)).

Additionally, because wind power production is variable, other generators will have to ramp to fill in the gaps when wind speeds are low. Wind farms that require less ramping from other generators are therefore more valuable. Thus, when considering the temporal aspects of wind power, the problem of where to site wind farms (remote or local locations) becomes much less trivial than simply comparing capacity factors and transmission costs.

Hoppock and Patiño-Echeverri (2010) introduced a wind capacity expansion model to meet 10 TWh of new wind generation in MISO. They accounted for annual energy production at different wind farms as well as the transmission cost to access farms in distant locations such as Minnesota and Iowa. They find that given the high transmission cost to access more distant locations, it's more economical to build near lower-quality wind resources in Illinois. However, the authors also acknowledge that results depend on 
their transmission cost assumptions, which are based on limited data and may not reflect future costs. The transmission landscape is rapidly changing in the region, as demonstrated by the Multi Value Project portfolio, a $\$ 6.5$ billion initiative that will increase transmission interconnectivity throughout MISO (MISO, 2012a). Therefore, as Hoppock and Patiño-Echeverri (2010) point out, it's very difficult to make static assumptions about transmission costs and arrive at strong conclusions.

Ultimately, the decision to build wind farms in a remote region depends on the difference in transmission upgrade costs between regions. In this study, we estimate the difference in transmission upgrade costs needed to justify the decision to site wind farms in lower-quality sites that are closer to load. We refer to this as the "break-even transmission cost premium" to access remote wind farms. If the difference in transmission costs across regions is below the break-even value, then it is more economical to build wind capacity in the remote region. We do not make strict assumptions about transmission costs, and instead provide break-even cost premium values that can be used by decision makers with information on true transmission costs. No paper to date has used this approach when considering siting decisions for wind development.

We use MISO as a case study given its ambitious renewable goals. We denote Illinois as the "local" region and Iowa/Minnesota (MN-IA) or North/South Dakota (ND-SD) as the "remote" regions. We assume that new wind capacity must be built in either the local or remote region (or both) to meet 40 TWh per year of additional wind generation in MISO. This goal is equivalent to complying with the Renewable Portfolio Standards (RPS) in Illinois, Minnesota, and Missouri ${ }^{3}$. These 40 TWh of wind generation correspond to about $5.7 \%$ of total load in MISO. There is currently about 40 TWh of existing wind in MISO so with the additional wind built in our analysis, this percentage would increase to $11.6 \%$ [(MISO, 2015a), (MISO, 2015b)]. We develop an optimization model that minimizes total wind

\footnotetext{
${ }^{3}$ RPS Targets (Database of State Incentives for Renewables \& Efficiency (DSIRE), 2015) were compared to wind generation by state (U.S. Energy Information Administration, 2015) to estimate additionally required wind generation.
} 
installation and transmission costs to meet this target by selecting among a predetermined set of hypothetical wind farms. We account for each wind farm's energy value, capacity value, and the negative effects to dispatchable generators due to the variability in power output from the selected wind farms. No paper to date has included these temporal aspects of wind power production within a wind capacity expansion model. Finally, to calculate the "break-even transmission cost premium" to build wind farms in remote regions, we parameterize our transmission cost assumptions across different scenarios to see how the optimal solution changes (i.e., whether wind farms are built in Illinois versus MN-IA or ND-SD). We test how different assumptions affect these values in a comprehensive sensitivity analysis in Section 3.3.

This work contributes to the wind integration literature by presenting a conceptual framework for analyzing wind farm siting tradeoffs, and the numerical results reported here are meant as an approximation to study these tradeoffs in MISO. To demonstrate the usefulness of these results, we compare our estimates of "break-even transmission cost premiums" to historical transmission cost premiums in MISO. The work we present here is generalizable and could be fitted to data from other locations with strong remote wind areas such as Western vs. Eastern China or Northern Scotland vs. the rest of the United Kingdom. The computational time for the model developed for this analysis is less than 5 minutes and can be expanded upon and tested under multiple assumptions without introducing much computational complexity.

\section{METHODS AND DATA}

This analysis relies on a mixed-integer optimization model that minimizes annual costs and selects which wind farms to build, among a predetermined sample, in order to meet a specific annual wind generation target. The decision to build a farm is modeled with decision variable $b_{k}$ that takes the value of 1 if the wind farm $k$ is built, 0 otherwise. Total annual costs to meet the target are the difference between costs and revenues from the selected wind farms. On the costs side, we include the wind farm annualized 
installation costs (WCost $t_{k}[$ in $\left.\$ / \mathrm{MW}]\right)$, the fixed operation and maintenance costs $\left(\right.$ OMCost $_{k}$ [in $\left.\left.\$ / \mathrm{MW}\right]\right)$, and the annualized transmission upgrade costs $\left(\operatorname{TCost}_{k}[\mathrm{in} \$ / \mathrm{MW}]\right)$. Each of these costs is represented per unit of nameplate capacity, and is multiplied by the plant's respective nameplate capacity (NamePlateMW $W_{k}[$ in MW]). On the revenue side, we include capacity payments and the market value of the energy produced. The capacity payments are obtained by multiplying the capacity market price (CapPrice [in $\$ / \mathrm{MW}]$ ) by the percentage of capacity credit (CapCreditPercentage ${ }_{k}$ ) and the nameplate capacity of the farm (NamePlateMW $W_{k}[\mathrm{in} \mathrm{MW]).} \mathrm{The} \mathrm{energy} \mathrm{value,} \mathrm{or} \mathrm{fuel} \mathrm{savings} \mathrm{to} \mathrm{generators,} \mathrm{is} \mathrm{the}$ wind output at a farm $k$ in each hour $t$ wind $_{t, k}$, [in MW, multiplied by one hour, resulting in MWhour i.e., $\mathrm{MWh}])$ times the marginal energy component (MEC) of market prices in that hour $\left(M E C_{t}\right.$ [in \$/MWh]). Lastly, we also account for the costs of wind power variability. Variability in net load (total load minus wind generation) is a measure of system-level variability induced by having increasingly variable generation in the system. It represents the amount of load that conventional, dispatchable generators have to serve. We therefore include a penalty, NetLoadPenalty (\$/MWh), for any change in net load $\left(M W_{t}\right)$ between hours to reduce the system- level variability cost of the new wind farms. For all annualized terms, we use an $8 \%$ continuous discount rate. 


$$
\begin{aligned}
& \sum_{k=1}^{M} b_{k} \\
& \text { argmin } \\
& b_{k} \in M \\
& *\left(\begin{array}{c}
\text { WCost } \left._{k}+\text { OMCost }_{k}+\text { TCost }_{k}\right) * \text { NamePlatekW }_{k} \\
- \text { CapPrice }_{\text {CapCreditPercentage }} * \text { NamePlateMW }_{k}-\sum_{t=1}^{T} \text { wind }_{t, k} * M E C_{k}
\end{array}\right) \\
& +\sum_{t=1}^{T}\left(\text { NetLoadPenalty } *\left|M W_{t}-M W_{t-1}\right|\right) \\
& \text { s.t. } \quad M W_{t}=\operatorname{Load}_{t}-\sum_{k=1}^{M}\left(\text { wind }_{t, k} * b_{k}\right)-\text { existingWind } \quad \quad, \forall t \in T \\
& \sum_{t=1}^{T} \sum_{k=1}^{M}\left(\text { ind }_{t, k} * b_{k}\right) \geq \text { Annual Generation Target }
\end{aligned}
$$

Equation (2) shows that in every hour, net load (MW $\left[\right.$ in MW]) needs to equal the total load $\left(\operatorname{Load}_{t}\right)$ minus the power output of new wind farms $\left(\sum_{k=1}^{M}\left(\right.\right.$ wind $\left.\left._{t, k} * b_{k}\right)\right)$ and existing wind farms (existingWind $)$. Equation (3) imposes a constraint so that there are enough wind farms to meet an annual wind generation target. For the MISO case study included in this paper, we set this target to $40 \mathrm{TWh}$.

Wind output data. All the wind farm locations, capacity, and hourly wind power output ( $\left.w i n d_{t, k}\right)$ come from the EWITS dataset created by NREL ("Eastern Wind Interconnection and Transmission Study (EWITS),”2012). The EWITS dataset consists of 1,326 hypothetical wind sites in the Eastern Interconnection with an estimate for the maximum capacity of each farm and simulated wind power output from 2004 to 2006, in 10-minute increments. We use the 2006 hourly data for the 443 EWITS sites that are located in the MISO region, including North Dakota, South Dakota, Minnesota, Iowa, and Illinois. We also test how the results of this analysis change when using 2004 and 2005 data in a sensitivity analysis presented in Section 3.3. EWITS does not state whether existing wind farms are already operating in their simulated locations. We assume that each new farm would require 85 
acres/megawatt (MW) - based on the average of 161 projects reported by Denholm et al. (2009)- and exclude farms from the EWITS dataset that are within the footprint of existing farms. We use a dataset from the U.S. Geological Survey to identify existing farm locations (U.S. Geological Survey, 2015). In the final list of potential EWITS sites - 320 in total - all individual states have enough capacity to reach a generation target of $40 \mathrm{TWh}$ from wind farms, but the wind quality differs across states. We exclude wind farms in Indiana, Michigan, and Wisconsin because capacity factors of farms in these states are low compared to other states. In preliminary model scenarios, including farms in these states did not yield different results, but increased computational requirements substantially. Further, all wind farms from the EWITS dataset in Missouri are outside of the MISO region so they are excluded. Lastly, we assume that all wind farms have a transmission loss of 2.2\%, which is the reported average in MISO (MISO, 2016).

Installation and $O \& M$ costs. We assume that wind installation cost is $\$ 1,750 / \mathrm{kW}$ (which is the weighted average of 16 wind farms currently under construction ( $2 \mathrm{GW}$ total) reported in Wiser and Bolinger (2014)). In Section 3.3, we also include a sensitivity analysis of varying installation costs between $\$ 1,500 / \mathrm{kW}$ and $\$ 2,000 / \mathrm{kW}$. We assume fixed operation and maintenance costs are $\$ 51 / \mathrm{kW}$, based on the assumption for year 2014 used in the Wind Vision Report by the U.S. Department of Energy (2015). Finally, we assume a 20-year lifetime for each wind farm.

Transmission costs. As in Mills et al. (2009), we treat transmission costs as a function of wind farm capacity $(\$ / \mathrm{kW})$, not distance. This assumption reflects the fact that some wind farm projects can connect to the grid infrastructure that is nearby. Even a farm in North Dakota wouldn't necessarily need to build brand new transmission lines into major load centers (i.e., all the way to Chicago) to sell power into the grid. An individual farm may indeed need to build long transmission lines while another may only need to upgrade equipment at an existing substation (no distance component). Both would incur interconnection costs, but a distance-based cost metric does not account for this difference whereas a capacity-based 
metric does. Furthermore, using a distance-based cost metric requires knowing the transmission line distance required for each wind project, which is very project specific and thus difficult to generalize.

To account for capacity-based transmission costs, we rely on data from MISO's transmission interconnection queue, which is publically available (MISO, 2013b), and provides details of the required transmission upgrades (mandated by MISO) for different energy projects - including wind farms - across MISO from 2003 to 2013. Table 1 shows statistics of transmission costs from this dataset for wind farms in the states we consider. The median cost in North and South Dakota was $\$ 600-\$ 700 / \mathrm{kW}$ compared to $\$ 33 / \mathrm{kW}$ in Illinois. This difference is large because Illinois (containing about $25 \%$ of load in MISO) has a more robust transmission system than ND-SD (which contains about $4 \%$ of load) (U.S. Energy Information Administration, 2012). Therefore, wind farms in ND-SD typically need to build more infrastructure (new substations, new power lines, upgrades to existing power lines, etc.) to serve load in MISO compared to those in Illinois. A difference also exists between MN-IA and Illinois, although it is much smaller. Median interconnection costs in MN-IA were about $\$ 90 / \mathrm{kW}$, compared to $\$ 33 / \mathrm{kW}$ in Illinois. Again, this does not mean that all existing wind farms in MN-IA built transmission lines directly into Illinois - it means that historically, more infrastructure was needed to reliably connect wind farms in MN-IA to the MISO grid.

For the MISO case study included in this paper, we do not make strict assumptions about transmission costs in different states. Instead, we aim to identify how much more expensive (in $\$ / \mathrm{kW}$ ) would transmission costs in the remote area have to be so that it never makes economic sense to build wind farms anywhere except Illinois (closest to load). To do this, we construct scenarios with increasingly higher incremental transmission costs between remote states (MN-IA and ND-SD) and local areas (Illinois) and report when the most economical solution is to build farms only within Illinois. We range the transmission cost difference between regions by $\$ 0$ to $\$ 1,000 / \mathrm{kW}$, in $\$ 10$ increments, and refer to this difference as the "transmission cost premium". When this cost premium is $\$ 0 / \mathrm{kW}$, farms in remote 
regions with better wind resources are favored. As the difference increases, and transmission costs are higher in remote regions, more farms in Illinois are favored. The break-even transmission cost premium is the cost differential where the solution changes from some non-zero capacity built in remote regions to $100 \%$ of capacity built in Illinois. Figure 1 summarizes how we treat transmission costs in our model. We group Iowa and Minnesota together (MN-IA) as well as North and South Dakota (ND-SD) since transmission costs in these states were historically similar (see Table 1).

Marginal Energy Component (MEC). We use market price data to estimate energy value of wind power in each hour. Locational Marginal Prices (LMP) provide an approximation of the cost reductions that may result from adding a zero marginal cost resource like wind, as well as the temporal value of wind power ((Fripp and Wiser, 2008), (Lewis, 2010)). However, LMPs vary by price node (there are thousands of nodes across MISO) since they incorporate transmission congestion and can therefore be extremely volatile due to the sudden occurrence of congestion on the grid. MISO also publishes data on the marginal energy component of prices (MEC) per hour, which is the energy-only component of market prices that represents the marginal cost generation for meeting load across MISO. MEC is by definition uniform across the MISO territory since it does not include the cost of transmission congestion, which is internalized in LMPs. In this analysis, the energy value calculation relies on this MEC and strictly reflects the value that different wind farms offer in reducing the marginal costs (effectively the short-term fuel costs) of existing generators.

We present three additional scenarios in Section 3.3 to test the robustness of the energy value calculation. The first uses LMPs at different price hubs instead of MEC. The second uses the marginal costs of coal and gas generators (estimated using a simple dispatch model) to estimate energy value. Additionally, there is some indication that market prices (and thus energy value) may decline with increasing levels of wind capacity additions ((Hirth, 2013);(Mills and Wiser, 2014)). This reduction effect is not endogenous 
in our model. Therefore, we also include a scenario that explores how results would change under lower market prices. Our conclusions are robust to these sensitivities.

Capacity prices. We assume that capacity prices are equal to $\$ 150 / \mathrm{MW}-\mathrm{day}$. Our model assumes that wind farms will have an effective lifetime of 20 years, which means that the capacity price assumption should represent the expected average price over this timeframe. MISO procures capacity only two months ahead, as opposed to the neighboring grid (PJM, Pennsylvania, Jersey, Maryland Power Pool), which procures capacity three years ahead. Many attribute the large difference in capacity prices between these regions to this difference in procurement timeframe (Constellation, 2014). For example, in the 2014-2015 planning year, capacity prices in MISO ranged from $\$ 3.29$ - 16.75/MW-day compared to \$128-172/MW-day in PJM [(MISO, 2014) (PJM, 2014)]. Some argue that if MISO operated liked PJM by procuring capacity 3 years ahead, then MISO's capacity prices would be closer to those in PJM (Constellation, 2014). Furthermore, capacity prices in Illinois (where most load is in MISO, and where there are interconnections with PJM) are increasing and converging to those in PJM. In the 2015-2016 planning year, the MISO capacity price in Zone 4 (Illinois) was $\$ 150 / \mathrm{MW}$-day, compared to $\$ 134 / \mathrm{MW}$ day in PJM's Illinois zone (ComEd) ((MISO, 2015c), (PJM, 2015)). Moreover, a capacity price of \$150/ MW-day is the midpoint between the lowest MISO capacity price in the 2014-2015 planning year (\$16.75/MW-day) and the absolute maximum price that one might observe in the market ( $\$ 300 / \mathrm{MW}$ day which is equivalent to the cost to build a new natural gas plant $)^{4}$. $\$ 150 / \mathrm{MW}$-day reflects a reasonable "base case" value between the possible extremes. Finally, in Section 3.3 we include a sensitivity analysis that relies on a lower capacity price $(\$ 17 / \mathrm{MW}$-day) and show that our conclusions are robust to this sensitivity.

\footnotetext{
${ }^{4}$ Assuming $\$ 13.17 / \mathrm{kW}$-yr in fixed overhead costs and $\$ 917 / \mathrm{kW}$ in overnight capital costs, annualized over 20 years with an $8 \%$ discount rate (U.S. Energy Information Administration, 2014).
} 
Capacity credits. We use the same method as MISO's to calculate wind capacity credits (the percentage of installed wind capacity that receives capacity payments) by first calculating the capacity factor for each wind farm (320 total) for the top 8 peak load hours of $2014\left(\operatorname{Load}_{k}\right)$. These capacity factors are then multiplied by a scalar of $\mathrm{K}=0.65$, which represents MISO's ratio of effective load carrying capacity (ELCC) to the weighted average of wind farm capacity factors during peak hours ${ }^{5}$. The result is a capacity credit percentage that ranges from $3 \%$ to $26 \%$, with an average of $11 \%$. For comparison, in the 2014-2015 planning year in MISO, the system-wide average wind capacity credit percentage was $12 \%$ (17.39\% capacity factor at peak load hours multiplied by K=0.7) (MISO, 2013a).

Variability costs. Apt (2007) shows that most of wind variability occurs across a frequency of hours and slow-ramping conventional generators, such as coal and gas-fired power plants, can balance the variability. This inter-hour variability, however, creates an added cost to conventional generators that must ramp under suboptimal conditions. For example, in their model of PJM, Oates and Jaramillo (2013) show that increasing wind generation to $20 \%$ increases coal startup costs. Balancing the variability of wind could increase the need to maintain increased reserves, which would also increase costs (Mauch et al., 2013). Our model captures this increased cost of variability at an hourly scale.

One common approach used to estimate variability costs is what DeMeo et al. (2005) refer to as "cost of service studies", which is the cost of serving the portion of system load not served by wind (i.e., net load). As wind increases, conventional generators may have to ramp up and down more regularly to respond to the variability in wind power (which can't be dispatched), and therefore the dispatchable generators incur higher costs. On the other hand, some of the variability may coincide with variability in load, thus providing a benefit to the grid. In order to capture the potentially mixed effects of variable wind output, studies increasingly rely on net load to evaluate grid integration issues (see for example Fertig et al.

\footnotetext{
${ }^{5}$ This analysis uses value $\mathrm{K}=0.65$, which is the average of the last two planning years ((MISO, 2012b), (MISO, 2013a))
} 
(2012) and Mauch et al. (2013)). Using dispatch models of all generators in a system and comparing operation costs with and without new wind power, it is possible to estimate the net change in the costs of dispatching power plants and divide by total increased wind generation to arrive at variability costs measured in \$/MWh. To evaluate these variability costs, DeMeo et al. (2005) perform a meta-analysis of different studies that calculated the effect of wind variability and uncertainty on grid operation costs. They find that studies' total costs range from $\$ 2$ - \$5/MWh of wind energy. Wiser and Bolinger (2014) show similar integration costs (some including both variability and transmission costs) for more recent studies.

We are interested in measuring the relative difference in variability impacts across different farms that can be selected, not an exact measure of variability costs due to wind power penetration. Therefore, we rely on a modeling approach that provides a functional approximation of the relative difference in variability costs across farms, since all farms are subject to the same assumptions. We choose this approach to help reduce model complexity, reduce computational time, and increase our model's generalizability to other regions. To penalize net load variability, we rely on 2014 load data for MISO (MISO, 2015b) and assume a penalty of \$10/ MWh for each hourly change in net load. This number is equal to the average ancillary service price in MISO in 2014, which we use as a proxy for this penalty (MISO, 2015d). In Section 3.3, we also include a sensitivity analysis to test whether lower ( $\$ 5 / \mathrm{MWh}$ ) and higher (\$20/MWh) net load variability cost assumptions affect the results of this analysis and find that results change by less than $10 \%$.

This approach for modeling variability cost is a simplification of the models described in DeMeo et al. (2005) since we don't directly measure the additional cost to generators resulting from net load variability across time. Instead, we use a proxy of $\$ 10$ for each hourly change in net load. Nonetheless, we arrive at costs that are within a reasonable margin of error of past studies. We estimate that total variability costs in 
our model (using $\$ 10 / \mathrm{MWh}$ net load penalty) are about $\$ 5 / \mathrm{MWh}$ of total wind generation $(\sim 200$ million for $40 \mathrm{TWh}$ of wind per year).

We do not include the option to build grid-level energy storage, which has been shown to reduce hourly variability effects on the grid and decrease transmission costs to access remote wind farms. Past research has shown that, in MISO, this application of energy storage is uneconomic for realistic technology solutions (grid batteries and compressed-air-energy-storage - CAES - facilities) at current as well as projected costs ((Lamy et al., 2014), (Denholm and Sioshansi, 2009)). Low natural gas prices have further hindered the development of storage projects, in particular CAES, as noted in Schulte et al. (2012).

Assumption summary. Table 2 lists all our base case assumptions. Section 3.3 also includes a sensitivity analysis to several of these assumptions, noted with “**” in Table 2. We solve the model using CPLEX in GAMS v23.6.

\section{RESULTS AND DISCUSSION}

\subsection{Break-even transmission costs to access remote regions}

Figure 2 shows the tradeoff between transmission costs to access remote regions, and the benefits of accessing high quality wind resources in those areas. Figure 2A highlights the trade-offs between building wind in Minnesota and Iowa (MN-IA) versus in Illinois, whereas Figure 2B shows the trade-offs of building wind in North or South Dakota (ND-SD) versus in Illinois. The horizontal axis varies the assumed incremental transmission cost (or "transmission cost premium") of building wind farms remotely instead of locally, represented in $\$ / \mathrm{kW}$ of installed wind. The vertical axis shows the percentage of total capacity built in each state under the least cost optimization defined in equations 1 to 3 in Section 2 to 
meet $40 \mathrm{TWh}$ of new wind generation in MISO. The lines in Figure 2 are not smooth and move in steps depending on the transmission cost scenario because of the integer nature of the solution.

The total capacity built across the different scenarios ranges from 10.5 to $11.2 \mathrm{GW}$. As noted in Figure $2 \mathrm{~A}$, if there is no transmission cost premium for MN-IA wind farms, then the least cost solution is to build most wind farms in MN-IA ( $84 \%$ of $10.8 \mathrm{GW}$ ) given their better wind resources. Between $\$ 0$ and $\$ 250 / \mathrm{kW}$, between $0 \%$ and $84 \%$ of capacity is built in MN-IA. Once the cost premium reaches $\$ 250 / \mathrm{kW}$, not even the locations with the best wind resources in MN-IA are selected; instead, the least cost solution is to build all capacity within Illinois $(11.2 \mathrm{GW})$. When transmission costs are the same in Illinois and in MN-IA, the least cost solution still includes some Illinois wind farms (1.7 GW) that have comparable capacity factors than those in MN-IA. Figure 2B illustrates similar results for the decision to build in NDSD or in Illinois. When there is no cost premium, the least-cost solution is to build $100 \%$ of the needed capacity in ND-SD. Once the cost premium reaches $\$ 360 / \mathrm{kW}$, the least cost solution is to build all capacity within Illinois $(11.2 \mathrm{GW})$. Therefore, $\$ 250 / \mathrm{kW}$ and $\$ 360 / \mathrm{kW}$ represent the break-even transmission cost premiums to build in MN-IA or ND-SD versus Illinois.

One way to better understand the meaning of these break-even values is to compare them to historical transmission upgrade costs. For example, as noted in Table 1 in Section 2, the median of historical transmission upgrade costs for wind farms in MN-IA was about $\$ 50 / \mathrm{kW}$ more costly than in Illinois $(\$ 85-$ 95 compared to $\$ 33$ ). This is well below the estimated break-even cost premium of $\$ 250 / \mathrm{kW}$. We therefore expect that building wind farms in MN-IA is more economical than in Illinois. In fact, given the median of historical costs, the results in Figure 2A suggest that it's best to build about $70 \%$ of all wind capacity in MN-IA, and the rest in Illinois (when $\mathrm{x}$-axis $=\$ 50 / \mathrm{kW}$ ). Under the same conditions, if decision-makers decided instead to build every wind farm in Illinois (100\% instead of 30\%), total costs would be higher by about $\$ 50$ million per year, or $\$ 500$ million over the lifetime of the wind projects (discounted at $8 \%$ over 20 years). The opposite result holds for ND-SD when comparing the estimated 
break-even values to historical transmission costs. Although North and South Dakota have some of the best wind resources in MISO, the required transmission costs to access wind farms in these states could only be up to $\$ 360 / \mathrm{kW}$ more costly than in Illinois to incentivize development. Historically the difference in transmission costs between the Dakotas and Illinois have been about double this break-even value.

These conclusions are meant as an approximation based on a comparison between historical transmission costs and the break-even values estimated for this paper. Our main contribution is in providing estimates of the break-even cost premiums, which can help decision-makers choose optimal siting locations given their information on transmission costs for specific projects.

\subsection{Driving factors for optimal decisions}

Table 3 shows the different value and cost components that contribute to the solutions presented in Figure 2. Overall, if transmission costs are the same across all states, building wind farms in remote sites can reduce the cost of meeting renewable energy targets. Most of the benefits of accessing wind resources in remote regions come from building farms with higher capacity factors, which yield lower wind installation and O\&M costs, the largest costs in all scenarios. Total costs to install and operate wind farms range from $\$ 2.4$ to $\$ 2.6$ billion per year ( $\$ 58$ to $\$ 65 / \mathrm{MWh}$ when normalized by wind generation, which is consistent with estimates reported in Lazard's Levelized Cost of Energy Analysis (2014)). The weighted average capacity factor for farms selected in the "MN-IA" and "ND-SD" solutions are 44.5\% and 45.7\%, respectively, compared to $42.9 \%$ in the "Illinois" solution. This difference yields a reduction in installation and O\&M costs of $\$ 95$ and $\$ 163$ million per year, respectively (Table 3). There are also improvements in energy value of wind totaling \$23 and \$43 million per year, respectively, due to the higher correlation between MEC and wind production for farms selected in the "MN-IA" and "ND-SD" solutions. Surprisingly, capacity value is higher for farms in Illinois, which slightly reduces the benefits of accessing remote regions. For example, without including capacity value in the model, total benefits of building farms in MN-IA and ND-SD would be overstated by about 25\%. Lastly, wind farms in MN-IA 
and ND-SD benefit from slightly lower net load cost (i.e., there is less net load variability), resulting in $\$ 6$ to $\$ 8$ million per year in savings compared to the "Illinois" solution (Table 3).

\subsection{Sensitivity Analysis}

Figure 3 summarizes a sensitivity analysis we performed to test how different model assumptions affect our main results, the break-even cost premium of transmission between Illinois versus MN-IA and NDSD. Base case results are noted in green squares, and correspond to results presented in Sections 3.1 and 3.2. Circles represent new scenarios that deviate from the assumptions described in Section 2. As evident from Figure 3, all results from the alternative scenarios yield the same conclusions when compared to historical transmission costs. The break-even transmission cost premiums of MN-IA are always higher than the median historical cost difference between MN-IA and Illinois, and those of ND-SD are always lower than the median historical cost difference between ND-SD and Illinois. Table 4 provides more information about these alternative scenarios.

\section{CONCLUSIONS AND POLICY IMPLICATIONS}

The lack of transmission infrastructure, or perceived high transmission costs, should not necessarily be the reason to dismiss wind projects in remote areas with high wind resources. It's important to consider the overall system net benefits of the potential siting locations. Knowing these benefits might reveal that it's worth investing in the transmission infrastructure to access them. This paper presents a computationally efficient optimization model that can be used to estimate net benefits and calculate the break-even transmission cost premium needed to access remote areas in MISO. Future transmission costs are highly uncertain, and therefore we treat them parametrically, providing a decision-space that decisionmakers with better cost information can populate to identify the optimal siting decision. We also show that the temporal value of the wind power has to be included in a wind capacity expansion model. For 
example, we find that excluding capacity value of wind farms (which depends on when wind farms produce energy) could misrepresent the benefits of building certain farms by $25 \%$.

This analysis also provides insights about tradeoffs between wind resource quality and transmission costs in MISO. The results suggest that accessing windy areas in states like Minnesota and Iowa, compared to building wind farms in Illinois, provides a lower-cost option to meeting a wind energy target of $40 \mathrm{TWh}$ per year in MISO. In fact, the total costs of meeting this target with wind farms in Iowa and Minnesota could be $\$ 1$ billion lower than relying on wind farms in Illinois, if transmissions costs are ignored. However, once the transmission cost premium to build a wind farm in Minnesota and Iowa reaches $\$ 250 / \mathrm{kW}$ or above, the best strategy is to build $100 \%$ of the capacity in Illinois. Similarly, the break-even transmission cost premium to access North and South Dakota is $\$ 360 / \mathrm{kW}$.

The break-even transmission cost premiums reported in this paper may enable project developers and policy makers to evaluate the economic worth of transmission projects in MISO. Consider for example the Rock Island Clean Line, a 3.5 GW high voltage DC transmission line being planned from Iowa to Illinois and states further East. This project is expected to cost approximately \$2 billion (Clean Line Energy Partners, 2015), or about $\$ 570 / \mathrm{kW}$ of installed wind capacity. This results in a transmission cost premium for MN-IA wind farms of $\$ 537 / \mathrm{kW}$ (given that transmission costs in Illinois are $\$ 33 / \mathrm{kW}$, the historical median). This cost premium is about double our estimated break-even value for MN-IA, suggesting that it's more economical to build wind farms in Illinois rather than building the Rock Island Clean Line to access MN-IA farms. There may be other factors not considered in this paper that justify building this line, such as the feasibility of siting certain wind projects or transmission lines over others, permitting issues, or the benefits of reducing transmission congestion across price nodes in MISO. Nonetheless, our findings provide a first-order approximation of the benefits of the Rock Island project, and other transmission projects like it. 
The method and model developed in this paper could be generalized to other areas in the world. For example, wind power in China shares a similar geographical trend than in the Midwest. China's most abundant wind resources are located in the Northwest, whereas most demand is located in the East (Liu and Kokko, 2010). Past research suggested that lack of transmission capacity has hindered wind development, and even limited the use of existing wind farms in China (Wu et al., 2014). It would therefore be useful to estimate the break-even transmission cost premium that would justify accessing resource-abundant regions. Our modeling framework could also be applied to assessing the economic break-even cost of building offshore wind farms versus onshore ones. Such an analysis may help policymakers justify investments in offshore wind development.

Finally, we note that other aspects, such as public acceptability, effects on local economies (such as direct and indirect job creation) will also determine decisions about where to site wind projects. While these aspects are outside the scope of this study, they certainly deserve attention.

\section{ACKNOWLEDGEMENTS}

This work was funded in part by the Center for Climate and Energy Decision Making (SES-0949710 and SES-1463492), through a cooperative agreement between the National Science Foundation and Carnegie Mellon University. The Doris Duke Charitable Foundation, the Richard King Mellon Foundation, the Electric Power Research Institute, and the Heinz Endowment also provided support through the RenewElec project at Carnegie Mellon University. Finally, the U.S. Environmental Protection Agency (EPA) provided support through the STAR Fellowship Assistance Agreement no. FP-91763701-0. None of the funding agencies formally reviewed this paper. Findings and recommendations are the sole responsibility of the authors and do not necessarily represent the views of the sponsors. Further, none of the funding agencies endorse any products or commercial services mentioned in this work. 
The authors would also like to thank Granger Morgan, Manuel V. Loureiro, Roger Lueken, and all others at the Climate and Energy Decision Making Center and at the Carnegie Mellon Electricity Industry Center who provided helpful comments on this work. 


\section{REFERENCES}

Apt, J., 2007. The spectrum of power from wind turbines. J. Power Sources 169, 369-374. doi:10.1016/j.jpowsour.2007.02.077

Clean Line Energy Partners, 2015. Rock Island Clean Line - Project Description [WWW Document]. URL http://www.rockislandcleanline.com/site/page/project-description

CME Group, 2016. Henry Hub Futures Price for December 2020.

Constellation, 2014. Illinois electric capacity market commentary. Ill. Manuf.

Database of State Incentives for Renewables \& Efficiency (DSIRE), 2015. Database of State Incentives for Renewables \& Efficiency (DSIRE) [WWW Document]. URL http://dsireusa.org/incentives/incentive.cfm?Incentive_Code $=$ IL04R\&re $=0 \&$ ee $=0$

DeMeo, E.A., Grant, W., Milligan, M.R., Schuerger, M.J., 2005. Wind plant integration [wind power plants]. IEEE Power Energy Mag. 3, 38-46. doi:10.1109/MPAE.2005.1524619

Denholm, P., Hand, M., Jackson, M., Ong, S., 2009. Land-Use Requirements of Modern Wind Power Plants in the United States.

Denholm, P., Sioshansi, R., 2009. The value of compressed air energy storage with wind in transmissionconstrained electric power systems. Energy Policy 37, 3149-3158. doi:10.1016/j.enpol.2009.04.002

Eastern Wind Interconnection and Transmission Study (EWITS), 2012. . Natl. Renew. Energy Lab. EIA, 2015. Annual Energy Outlook 2015. US Energy Inf. Adm. Table A3 Energy Prices Sect. Source.

EPA, 2014. Emissions \& Generation Resource Integrated Database (eGRID) - year 2010. US Environ. Prot. Agency.

Fertig, E., Apt, J., Jaramillo, P., Katzenstein, W., 2012. The effect of long-distance interconnection on wind power variability. Environ. Res. Lett. 7, 34017. doi:10.1088/1748-9326/7/3/034017

Fripp, M., Wiser, R.H., 2008. Effects of Temporal Wind Patterns on the Value of Wind-Generated Electricity in California and the Northwest. IEEE Trans. Power Syst. 23, 477-485. doi:10.1109/TPWRS.2008.919427

Hirth, L., 2013. The market value of variable renewables: The effect of solar wind power variability on their relative price. Energy Econ. 38, 218-236. doi:10.1016/j.eneco.2013.02.004

Hoppock, D.C., Patiño-Echeverri, D., 2010. Cost of Wind Energy: Comparing Distant Wind Resources to Local Resources in the Midwestern United States. Environ. Sci. Technol. 44, 8758-8765. doi:10.1021/es100751p

Lamy, J., Azevedo, I.L., Jaramillo, P., 2014. The role of energy storage in accessing remote wind resources in the Midwest. Energy Policy 68, 123-131. doi:10.1016/j.enpol.2014.01.008

Lazard's Levelized Cost of Energy Analysis, 2014.

Lewis, G.M., 2010. Estimating the value of wind energy using electricity locational marginal price. Energy Policy, Large-scale wind power in electricity markets with Regular Papers 38, 32213231. doi:10.1016/j.enpol.2009.07.045

Liu, Y., Kokko, A., 2010. Wind power in China: Policy and development challenges. Energy Policy, The socio-economic transition towards a hydrogen economy - findings from European research, with regular papers 38, 5520-5529. doi:10.1016/j.enpol.2010.04.050

LMP Map, 2016. . MISO Available at: www.misoenergy.org.

Mauch, B., Apt, J., Carvalho, P.M.S., Jaramillo, P., 2013. What day-ahead reserves are needed in electric grids with high levels of wind power? Environ. Res. Lett. 8, 34013. doi:10.1088/17489326/8/3/034013

Mills, A. d., Wiser, R. h., 2014. Changes in the economic value of wind energy and flexible resources at increasing penetration levels in the Rocky Mountain Power Area. Wind Energy 17, 1711-1726. doi:10.1002/we.1663 
Mills, A., Wiser, R., Porter, K., 2009. The Cost of Transmission for Wind Energy: A Review of Transmission Planning Studies.

MISO, 2016a. MISO Transmission Owner Loss Data.

MISO, 2016b. MISO generation fuel mix dataset, 2014.

MISO, 2015a. 2014 Historical Hourly Wind Generation [WWW Document]. MISO Mark. Rep. URL https://www.misoenergy.org/Library/MarketReports/ (accessed 1.10.15).

MISO, 2015b. 2014 Daily Regional Forecast and Actual Load [WWW Document]. URL https://www.misoenergy.org/Library/MarketReports/ (accessed 1.10.15).

MISO, 2015c. 2015/ 2016 Planning Resource Auction Results.

MISO, 2015d. 2014 Real-Time Final Market MCPs [WWW Document]. Real-Time Mark. Data. URL https://www.misoenergy.org/https://www.misoenergy.org/Library/MarketReports/ (accessed 1.10.15).

MISO, 2015e. 2014 Real-Time Final Market LMPs [WWW Document]. MISO Mark. Rep. URL https://www.misoenergy.org/Library/MarketReports/ (accessed 1.10.15).

MISO, 2014. 2014/2015 MISO Planning Resource Auction Results.

MISO, 2013a. Planning Year 2014-2015 Wind Capacity Credit.

MISO, 2013b. Interconnection Queue [WWW Document]. URL www.misoenergy.org (accessed 9.1.13).

MISO, 2012a. Multi Value Project Portfolio: Results and Analyses. MISO.

MISO, 2012b. Planning Year 2013-2014 Wind Capacity Credit.

MISO Transmission Expansion Planning (MTEP) report, 2015. . MISO.

Oates, D.L., Jaramillo, P., 2013. Production cost and air emissions impacts of coal cycling in power systems with large-scale wind penetration. Environ. Res. Lett. 8, 24022. doi:10.1088/17489326/8/2/024022

PJM, 2015. 2015/ 2016 Auction Results for All Incremental Auctions \& Base Residual Auction.

PJM, 2014. 2014/ 2015 Auction Results for All Incremental Auctions \& Base Residual Auction.

Schulte, R.H., Critelli, N., Holst, K., Huff, G., 2012. Lessons from Iowa: Development of a 270 Megawatt Compressed Air Energy Storage Project in Midwest Independent System Operator. Sandia Natl. Lab. SAND2012-0388.

Tegen, S., Hand, M., Maples, B., Lantz, E., Schwabe, P., Smith, A., 2012. 2010 Cost of Wind Energy Review.

U.S. Department of Energy, 2015. Wind Vision: A New Era for Wind Power in the United States (No. DOE/GO-102015-4557). U.S. Department of Energy.

U.S. Energy Information Administration, 2015. Net Generation by State by Type of Producer by Energy Source [WWW Document]. URL https://www.eia.gov/electricity/data/state/

U.S. Energy Information Administration, 2014. Assumptions to the Annual Energy Outlook 2014. U.S. Energy Information Administration.

U.S. Energy Information Administration, 2012. Retail Sales of Electricity by State by Sector by Provider [WWW Document]. URL https://www.eia.gov/electricity/data/state/

U.S. Geological Survey, 2015. Wind Turbine Interactive Web Map [WWW Document]. URL http://eerscmap.usgs.gov/windfarm/

Venkatesh, A., Jaramillo, P., Griffin, W.M., Matthews, H.S., 2012. Implications of Near-Term Coal Power Plant Retirement for SO2 and NOX and Life Cycle GHG Emissions. Environ. Sci. Technol. 46, 9838-9845. doi:10.1021/es3023539

Wiser, R., Bolinger, M., 2014. 2013 Wind Technologies Market Report.

Woo, C.K., Horowitz, I., Moore, J., Pacheco, A., 2011. The impact of wind generation on the electricity spot-market price level and variance: The Texas experience. Energy Policy, Special Section: Renewable energy policy and development 39, 3939-3944. doi:10.1016/j.enpol.2011.03.084

Wu, Z., Sun, H., Du, Y., 2014. A large amount of idle capacity under rapid expansion: Policy analysis on the dilemma of wind power utilization in China. Renew. Sustain. Energy Rev. 32, 271-277. doi:10.1016/j.rser.2014.01.022 
Table 1: Historical transmission costs per state $(2014 \$ / \mathrm{kW}$ of wind capacity).

\begin{tabular}{|l|ccc|c|}
\hline \multicolumn{3}{|c|}{} & \multicolumn{3}{c|}{$\begin{array}{c}\text { Percentile } \\
\mathbf{5 0}^{\text {th }}\end{array}$} & $\mathbf{7 5}^{\text {th }}$ & $\begin{array}{c}\text { \# Observations } \\
\text { in dataset }\end{array}$ \\
\hline IL & $\$ 22$ & $\$ 33$ & $\$ 115$ & 29 \\
IA & $\$ 55$ & $\$ 95$ & $\$ 180$ & 20 \\
MN & $\$ 50$ & $\$ 85$ & $\$ 158$ & 51 \\
SD & $\$ 267$ & $\$ 622$ & $\$ 727$ & 29 \\
ND & $\$ 264$ & $\$ 762$ & $\$ 1,117$ & 39 \\
\hline
\end{tabular}

In the most recent queue database (MISO, 2013b) there were 338 wind farms with publically available transmission cost estimates in the states analyzed in this paper. Observations that recorded $\$ 0 / \mathrm{kW}$ in upgrades were excluded since these cases were for smaller projects and don't reflect the costs necessary to comply with $40 \mathrm{TWh}$ of new wind generation. Some cost calculations in the queue dataset accounted for the recent Multi-Value transmission projects (MVP) in MISO, which are designed to reduce interconnection costs in MISO (MISO, 2012a). Sufficient data (sample >20) for wind farms including MVP were only available for Iowa and Minnesota, which is not surprising since these states are the principle benefactors of the MVP projects. Thus the transmission cost estimates in this table for Iowa and Minnesota are derived from the subset of observations that included MVP projects (71 total); the other state cost estimates are derived from both MVP and nonMVP observations inclusive (97 total). The final dataset includes 168 different cost estimates (adjusted to 2014 \$) from projects proposed between 2003 and 2013.

Table 2: Base case model assumptions.

\begin{tabular}{lcc}
\hline & Base Case & Source \\
\hline Wind capital costs $(\$ / \mathrm{kW})$ & $\$ 1,750^{* *}$ & (Wiser and Bolinger, 2014) \\
Fixed O\&M (\$/kW-year) & $\$ 51$ & (U.S. Department of Energy, 2015) \\
Transmission capital costs $(\$ / \mathrm{kW}$ of wind) & Parameterized & (Tegen et al., 2012) \\
Wind farm lifetime (years) & 20 & (Wiser and Bolinger, 2014) \\
Transmission lifetime (years) & 40 & (“Eastern Wind Interconnection and \\
Discount rate $(\%)$ & $8 \%$ & Transmission Study (EWITS), 2012) \\
& & (MISO, 2015e) \\
Hourly wind output & 2006 EWITS** & (MISO, 2015b) \\
Hourly energy value & 2014 MCE** 2015a) \\
Hourly load & 2014 MISO & (MISO, \\
Hourly existing wind generation & 2014 MISO & (MISO, 2013a) \\
Capacity Price $(\$ / M W-d a y) ~$ & $\$ 150^{* *}$ & Varies by farm, \\
Capacity Credit Percentage & based on MISO’s method & operating reserves in MISO in \\
\end{tabular}

** Sensitivities to these assumptions are presented in Section 3.3 
Table 3: Value (cost) of select model solutions presented in Figure 2 (\$ M/year) when assuming that transmission costs are the same across states.

\begin{tabular}{lccc|cc}
\hline \multicolumn{1}{c}{} & & & \multicolumn{2}{c}{$\begin{array}{c}\text { Difference from "Illinois" } \\
\text { Solution }\end{array}$} \\
\cline { 5 - 6 } \multicolumn{1}{c}{ Model solution } & MN - IA & ND $^{\mathbf{1}} \mathbf{S D}^{2}$ & Illinois $^{3}$ & MN - IA & ND - SD \\
\hline Energy Value & $\$ 1,572$ & $\$ 1,592$ & $\$ 1,549$ & $\$ 23$ & $\$ 43$ \\
Capacity Value & $\$ 83$ & $\$ 67$ & $\$ 113$ & $(\$ 30)$ & $(\$ 46)$ \\
Wind Installed + O\&M Cost & $(\$ 2,517)$ & $(\$ 2,449)$ & $(\$ 2,611)$ & $\$ 95$ & $\$ 163$ \\
Net Load Penalty Cost & $(\$ 194)$ & $(\$ 192)$ & $(\$ 200)$ & $\$ 6$ & $\$ 8$ \\
& & & & & \\
\hline Net Cost & $(\$ 1,056)$ & $(\$ 982)$ & $(\$ 1,150)$ & $\$ 94$ & $\$ 168$ \\
\hline
\end{tabular}

1) $\$ 0 / k W$ in Figure $2 A, 2) \$ 0 / K W$ in Figure $2 B, 3) \$ 360 / K W$ in Figure $2 A$ and $B$ 


\section{Table 4: Description of additional model scenarios for sensitivity analysis presented in Figure 3}

\begin{tabular}{|c|c|}
\hline \multirow{2}{*}{$\begin{array}{l}\text { Alternative } \\
\text { energy value } \\
\text { calculations }\end{array}$} & $\begin{array}{l}\text { MCE and LMP: To calculate energy value, we test if using } 2014 \text { LMPs at different price nodes instead of } 2014 \text { MEC (marginal energy } \\
\text { component of prices in MISO) changes the main conclusions from our analysis. Wind farms in Minnesota are assigned to prices from the } \\
\text { "Minnesota Hub", farms in Illinois to the "Illinois Hub", farms in North and South Dakota to the "OTP.MPC" hub, and farms in Iowa to } \\
\text { the "ALTW.ALTW" hub. These hubs are identified using MISO's LMP Map (2016) and data for each price hub was downloaded directly } \\
\text { from (MISO, 2015e). } \\
\text { The resulting break-even transmission cost premium for ND-SD is } \$ 310 / \mathrm{kW} \text { compared to } \$ 360 / \mathrm{kW} \text { when using MEC (base case), still well } \\
\text { below historical transmission cost differentials. However, the break-even value in MN-IA (Figure } 3 \mathrm{~A} \text { ) is } \$ 100 / \mathrm{kW} \text { compared to } \$ 250 / \mathrm{kW} \\
\text { when using MCE (base case). This large difference for MN-IA is mainly driven by the difference in LMP prices between Minnesota Hub } \\
\text { (average of } \$ 31 / \mathrm{MWh)} \mathrm{and} \mathrm{the} \mathrm{Illinois} \mathrm{Hub} \mathrm{(average} \mathrm{of} \$ 35 / \mathrm{MWh),} \mathrm{which} \mathrm{lowers} \mathrm{the} \mathrm{energy} \mathrm{value} \mathrm{of} \mathrm{wind} \mathrm{farms} \mathrm{in} \mathrm{MN-IA,} \mathrm{thus} \mathrm{reducing} \\
\text { their competitiveness compared to Illinois farms. Nonetheless, we still arrive at the same conclusions since the difference in historical } \\
\text { transmission costs between MN-IA and Illinois are still well below } \$ 100 / \mathrm{kW} \text {. }\end{array}$ \\
\hline & $\begin{array}{l}\text { Simple Dispatch: We also run another scenario in which we estimated marginal costs to MISO generations in each hour, instead of relying } \\
\text { on MISO's marginal energy component (MEC) price data. For this analysis, we build a simple dispatch model of MISO generators based } \\
\text { on the analysis in Venkatesh et al. (2012). In the simplified dispatch model, we assume that in each hour, the marginal fuel source is either } \\
\text { coal or gas, and assume that all other fuel sources are fixed based on } 2014 \text { data from MISO on the historical generation mix (MISO, } \\
2016 \mathrm{~b} \text { ). We then assume a fuel price for coal of } \$ 2.38 / \mathrm{mmbtu} \text { based on EIA's annual energy outlook reference case in } 2015 \text { for year } 2020 \\
\text { (EIA, 2015). We assume that gas fuel costs are } \$ 3.27 / \mathrm{mmbtu} \text {, based on the Henry Hub futures price for December } 2020 \text { delivery (CME } \\
\text { Group, 2016). Coal and gas units are then dispatched (lowest cost first) to meet } 2014 \text { MISO load in each hour (MISO, } 2015 \mathrm{~b} \text { ) using } \\
\text { generators with heat rates and nameplate capacity from the U.S. EPA's EGRID dataset (EPA, 2014), which contains } 299 \text { coal and gas } \\
\text { generators in MISO. This analysis results in an hourly dataset of marginal fuel costs to meet load in each hour of } 2014 \text {. We then used this } \\
\text { result, instead of MEC prices, to estimate the energy value of wind farms in our site selection model. With this approach we find that the } \\
\text { resulting break-even transmission costs differ by about } 20 \%, \text { but yield the same qualitative conclusions (see Figure 3). }\end{array}$ \\
\hline $\begin{array}{l}\text { Wind model } \\
\text { year }\end{array}$ & $\begin{array}{l}\text { We rely on wind data from EWITS (2012), which spans } 2004 \text { through } 2006 \text {. In the base case, we choose } 2006 \text { as our sample year, but also } \\
\text { report results when using } 2004 \text { and } 2005 \text { model years in this section. We find that wind data in } 2004 \text { and } 2005 \text { is more favorable to wind } \\
\text { farms in remote areas (MN-IA and ND-SD) compared to Illinois, and thus the break-even transmission cost premiums for MN-IA and ND- } \\
\text { SD are higher when using these sample years compared to the base case. With the best wind year (2005) in our sample, the break-even } \\
\text { transmission cost premium of ND-SD is } \$ 620 / \mathrm{kW} \text {, which is close to, but below median historical cost premium. Similarly, in MN-IA the } \\
\text { best wind year yields a break-even cost premium of } \$ 450 / \mathrm{kW} \text {, which is well above the median historical cost premium. These results } \\
\text { suggest that even in the most extreme sample years in EWITS (2012), MN-IA (compared to ND-SD and Illinois) appears to be the most } \\
\text { economical location to comply with the MISO renewable targets. Furthermore, these sensitivities help demonstrate that wind power output } \\
\text { (i.e. capacity factor) is by far the most important driver of optimal siting decisions, and of our results. We continue to use } 2006 \text { as our base } \\
\text { case sample year for wind since it provides the most conservative results for the break-even transmission cost premiums. }\end{array}$ \\
\hline $\begin{array}{l}\text { Wind } \\
\text { capacity cost }\end{array}$ & $\begin{array}{l}\text { For the base case, we assume that overnight installed capital costs for wind farms are } \$ 1,750 / \mathrm{kW} \text {. Here we test installed costs of } \$ 1,500 / \mathrm{kW} \\
\text { and } \$ 2,000 / \mathrm{kW} \text {. We find that the break-even transmission costs change by less than } 10 \% \text { for both MN-IA and ND-SD. }\end{array}$ \\
\hline $\begin{array}{c}\text { Reduction in } \\
\text { market prices } \\
\text { due to } \\
\text { increased } \\
\text { wind } \\
\text { generation }\end{array}$ & $\begin{array}{l}\text { Market prices and their marginal energy component (MEC) are likely affected by increased transmission capacity and/or wind generation } \\
\text { on the grid. For example, Woo et al. (2011) shows that LMP prices tend to decrease with increasing amounts of wind capacity in Texas } \\
\text { (ERCOT). They estimate that a } 10 \% \text { increase in wind capacity leads to a } 2 \% \text { to } 9 \% \text { decrease in average LMP prices in ERCOT depending } \\
\text { on the zone they considered. As of June } 2014 \text {, there were about } 13.4 \text { GW of wind installed in MISO. For this analysis, we add about } 10 \\
\text { GW of wind capacity to MISO to meet the } 40 \text { TWh policy target, a } 75 \% \text { increase in wind capacity. Therefore, we expect a decrease in } \\
\text { market prices, perhaps by } 15 \% \text { to } 70 \% \text { if scaling the effects from Woo et al. (2011) linearly. Although we do not endogenize this effect in } \\
\text { our model, we run two alternative scenarios in which we scale MEC prices down by } 15 \% \text { and } 70 \% \text { to see the effect on the results. We find } \\
\text { that the " } 15 \% \text { scenario" reduces the estimated break-even transmission cost premium by } 5 \% \text {, and the " } 70 \% \text { scenario" reduces it by } 20 \% \text {. } \\
\text { This is unsurprising, as lower energy values partly eliminate the benefits of increased capacity factors in remote sites. }\end{array}$ \\
\hline $\begin{array}{l}\text { Capacity } \\
\text { price } \\
(\$ / M W-d a y)\end{array}$ & $\begin{array}{l}\text { We test how a low price assumption ( } \$ 17 / \mathrm{MW} \text {-day) affect the results compared to the base case assumption of } \$ 150 / \mathrm{MW} \text {-day. We find } \\
\text { that with a lower capacity price, the competitiveness of some Illinois wind farms (the best ones) diminishes, and therefore remote wind } \\
\text { farms in MN-IA and ND-SD become more competitive. Therefore, the transmission break-even cost premium for both MN-IA and ND-SD } \\
\text { increase by about } 20 \% \text {. }\end{array}$ \\
\hline & $\begin{array}{l}\text { To penalize net load variability in the base case, we assume a penalty of } \$ 10 / \mathrm{MWh} \text { for each hourly change in net load. We also test whether } \\
\text { lower }(\$ 5 / \mathrm{MWh}) \text { and higher }(\$ 20 / \mathrm{MWh}) \text { net load penalty assumptions affect results. We find these alternative scenarios change our } \\
\text { estimated break-even values by less than } 10 \% \text { for both MN-IA and ND-SD. }\end{array}$ \\
\hline
\end{tabular}


A

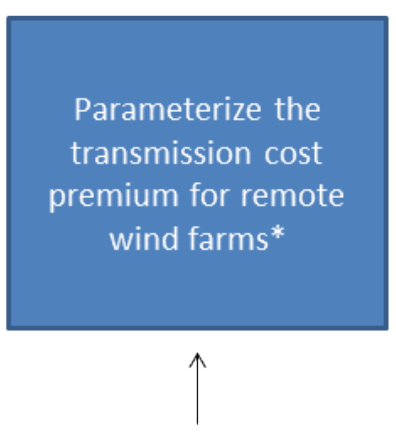

From $\$ 0$ to $\$ 1000 / \mathrm{kW}$ of wind capacity

* Additional transmission cost needed to build wind farms in remote regions compared to in Illinois
B

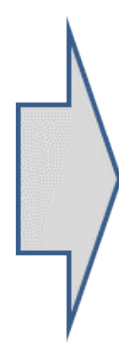

- Capacity value

- Energy value

- Hourly wind output

- Wind capital cost

Costs

- Transmission cost (from " $\mathrm{A}$ ")

- Variability cost
C
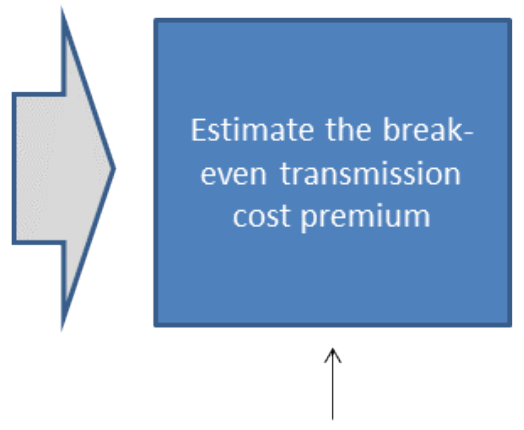

Observe the transmission scenario from " $\mathrm{A}$ " in which all wind capacity is built within Illinois, and not in the remote regions tested

Figure 1: Summary of modeling method to estimate the break even transmission cost premium to access remote wind farms

A

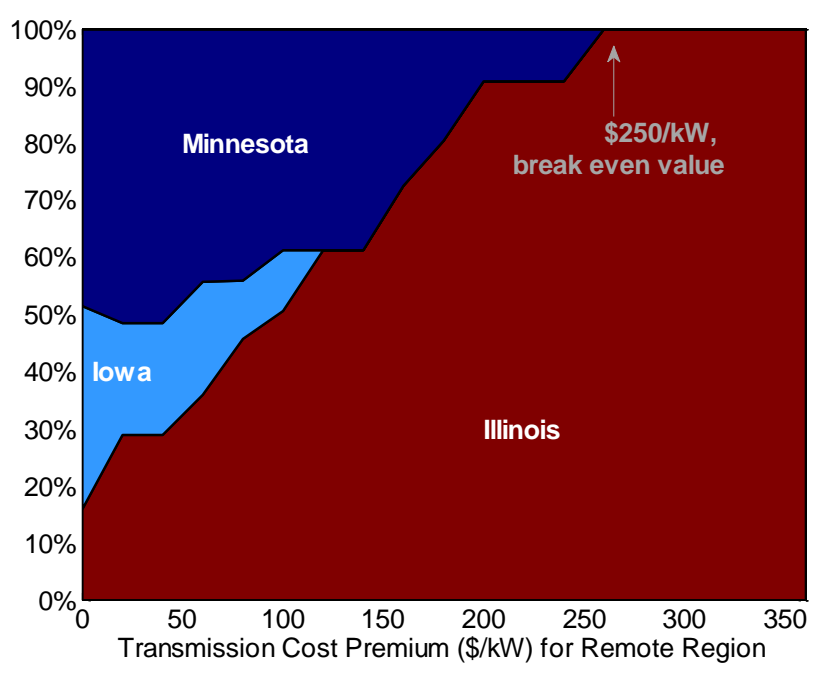

B

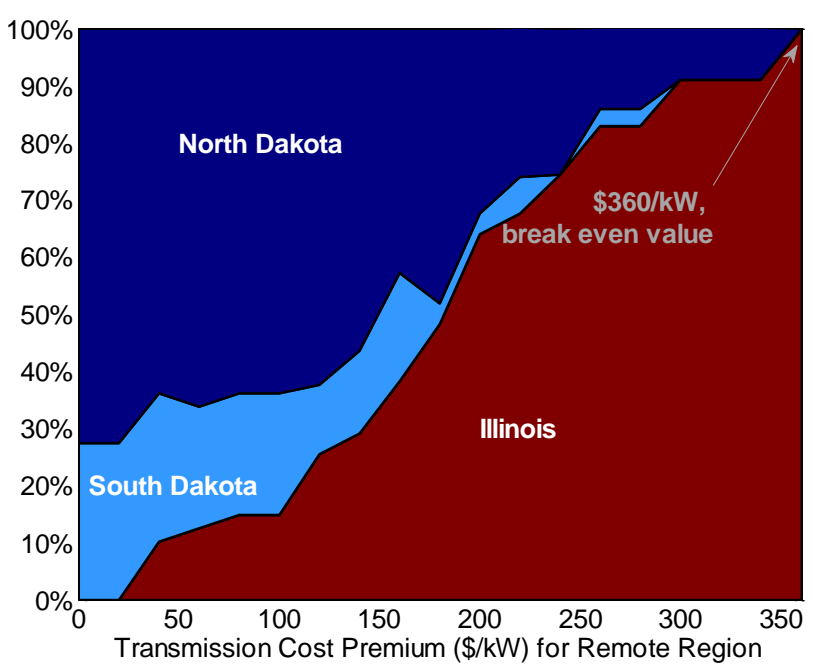

Figure 2: Model results showing the \% of capacity built in each state when varying transmission costs between remote states and Illinois $(\$ / \mathrm{kW}$ of wind capacity). 


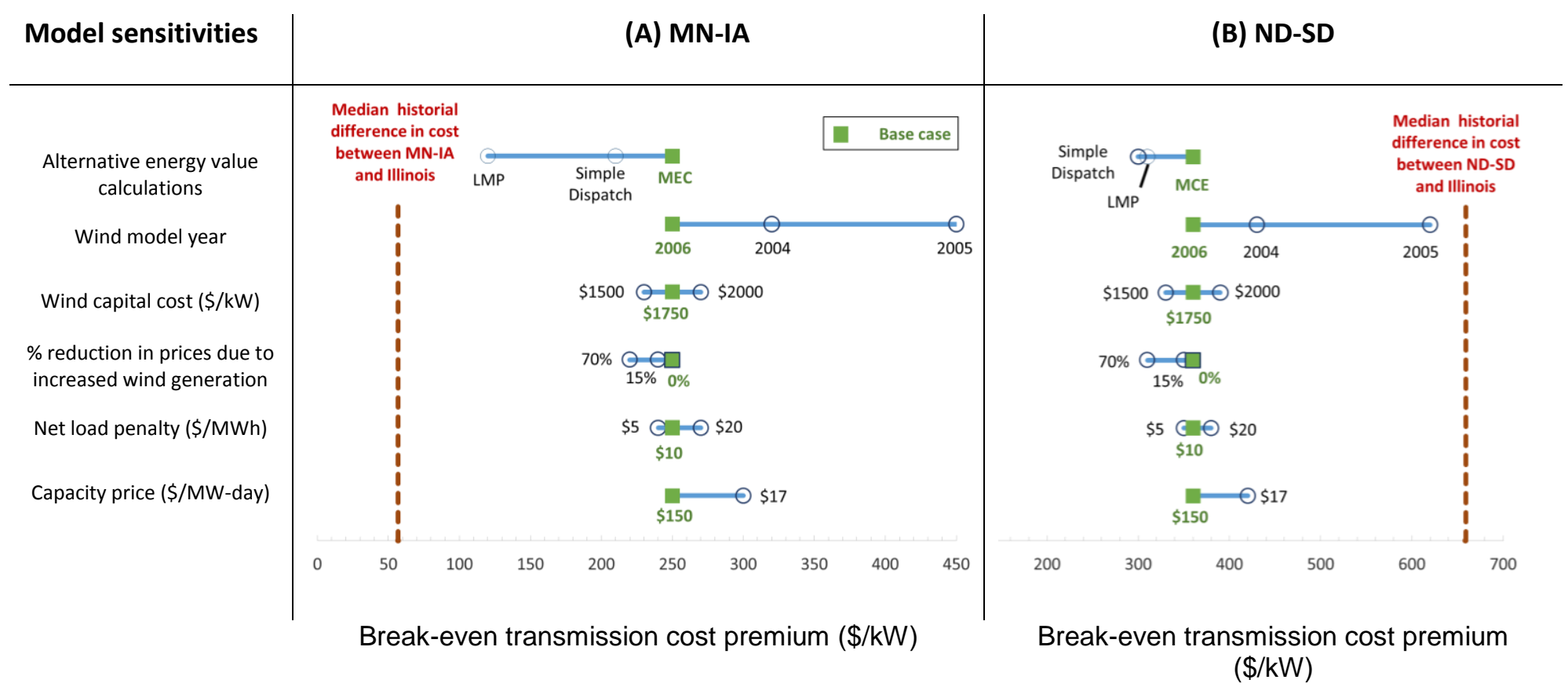

Figure 3: Tornado diagrams showing the resulting break-even transmission cost premium in MNIA (left) and ND-SD (right) when using different model assumptions. Green squares represent our base case assumptions. The red dashed lines show how results compare to median historical difference in transmission costs between the remote region and Illinois. 